\title{
Aseptic Meningitis among Children in Kuwait
}

\author{
Entesar H. Husain ${ }^{a} \quad$ Esmaeel Bahbahani $^{b}$ Faisal Al-Shawaf ${ }^{b}$ \\ Mamdooh Hasab El-Nabic Majdi Hilmi Shafiq ${ }^{\mathrm{d}}$ Nahid Al-Ateeqi ${ }^{\mathrm{e}}$ \\ Atef Abo Talibf \\ Departments of Pediatrics, ${ }^{a}$ Faculty of Medicine, Kuwait University, ${ }^{\mathrm{b}}$ Mubarak Al-Kabeer Hospital, \\ ${ }^{\mathrm{c}} \mathrm{Al}$-Adan Hospital, d Al-Farwania Hospital, e Al-Sabah Hospital, and ${ }^{\mathrm{f}} \mathrm{Al}$-Jahra Hospital, Kuwait
}

\section{Key Words}

Meningitis · Aseptic meningitis · Children in Kuwait

\begin{abstract}
Objective: To describe the epidemiology, clinical features, and the morbidity caused by aseptic meningitis in children in Kuwait. Subjects and Method: A multicenter retrospective study of previously healthy children hospitalized with a diagnosis of aseptic meningitis in the period 2001-2003 was carried out. Results: There were 172 children with the diagnosis of meningitis based on changes in the cerebrospinal fluid. Aseptic meningitis was diagnosed in 86 (50\%) of the cases; their mean age was $3.2 \pm 3.8$ years. There were two peaks of cases, one during the months of May and June and the other in November/December. Older children ( $\geq 5$ years) presented more frequently with signs and symptoms suggestive of meningeal irritation than younger children $(<5$ years) ( $p \leq 0.01$ ). The median duration of hospitalization was 7 days. The majority ( $n=56,65 \%$ ) received a 7- to 10 -day course of antibiotics despite negative cerebrospinal fluid cultures. Six (7\%) hospitalized children had complications: 3 had convulsions, 2 were ventilated, and 1 had motor palsy. Intensive care unit admission was necessary in 3. All the children were discharged home without sequelae. There were no mortalities in the study group. Conclusions: Aseptic
\end{abstract}

meningitis among children in Kuwait is a major cause of morbidity and requires prolonged hospitalization. The complication rate is low and there were no sequelae or mortality among the studied cohort. Copyright $\odot 2008$ S. Karger AG, Basel

\section{Introduction}

Aseptic meningitis is an inflammation of the meninges with sterile bacterial cultures of the cerebrospinal fluid (CSF) [1]. This form of meningitis is more common than bacterial meningitis. Viruses are the most common cause of aseptic meningitis, but the list of differential diagnosis is large and includes partially treated meningitis, tuberculous or fungal meningitis, collagen vascular disease and drug-induced meningeal irritation. Enteroviruses are the most common cause of viral aseptic meningitis in adults and children accounting for 80-90\% [2, 3]. They include echovirus, Coxsackie A and B viruses, polioviruses, and a variety of numbered enteroviruses.

In Kuwait, all children are routinely vaccinated against Haemophilus influenzae type b since 1996. In addition, a polysaccharide meningococcal vaccine (A, C, Y, and $\mathrm{W} 135)$ is administered routinely to all children at the age of 2 years. More recently in August 2006, a seven-valent

\section{KARGER \\ Fax +41613061234 \\ E-Mail karger@karger.ch}

www.karger.com
(C) 2008 S. Karger AG, Basel

1011-7571/08/0172-0122\$24.50/0

Accessible online at:

www.karger.com/mpp
Dr. Entesar H. Husain

Department of Pediatrics, Faculty of Medicine

Kuwait University, PO Box 24923

Safat 13110 (Kuwait)

Fax+965 543 0207, E-Mail entesar@qualitynet.net 
pneumococcal conjugate vaccine has been introduced into the immunization program. The epidemiological pattern of bacterial meningitis has been studied in $\mathrm{Ku}-$ wait $[4,5]$ but not that of aseptic meningitis. The purpose of this study was to investigate the seasonality, clinical and radiographic features, management and short-term outcome of children diagnosed with aseptic meningitis of presumed viral etiology.

\section{Subjects and Methods}

Meningitis is a notifiable disease in Kuwait. All cases of meningitis in children are notified to the Department of Preventive Medicine through multiple channels including: pediatricians, microbiologists or infection control officers. The Ministry of Health is the major provider of the health care system through six regional health care districts.

\section{Subjects}

Children 12 years of age and younger with a diagnosis of meningitis between January 2001 and December 2003 were identified through the review of the medical records of the Department of Preventive Medicine in the six governmental hospitals in Kuwait (Al-Amiri, Al-Adan, Mubarak Al-Kabeer, Al-Farwania, Al-Sabah and Al-Jahra hospitals). Demographic, clinical and laboratory data, management and clinical outcome were recorded in a standardized format. Cases were included if they had not received antibiotic therapy prior to lumbar puncture and had a final diagnosis of aseptic meningitis confirmed by CSF pleocytosis, negative Gram stain, negative latex agglutination test and negative CSF culture. The following normal CSF values were used: term neonate white blood cell (WBC) count $0-24 \mathrm{WBC} / \mathrm{mm}^{3}$, child $\mathrm{WBC}$ count $0-7 \mathrm{WBC} / \mathrm{mm}^{3}$ [6], glucose $3.9-6.1 \mathrm{mmol} / \mathrm{l}$, and protein $150-450 \mathrm{mg} / \mathrm{l}$. Children were excluded from analysis if they had bacterial meningitis, partially treated meningitis, or aseptic meningitis associated with other conditions such as the Kawasaki disease or any form of vasculitis, and encephalitis demonstrated clinically by an impaired level of consciousness.

\section{Statistics}

The data were processed using the Statistical Package for the Social Sciences for Windows version 10.0 (SPSS Inc., Chicago, Ill., USA). Basic statistical parameters (median, mean, frequency and proportions) were calculated. Significant differences among categorical variables were identified using the $\chi^{2}$ test; $p<0.01$ was considered to be significant.

\section{Results}

There were 211 cases of suspected meningitis in children reported to the Department of Preventive Medicine in all participating hospitals in Kuwait during the study period from 2001 to 2003. Of the 211 cases, lumbar puncture was performed in 172 patients: 67 (39\%) had bacte-

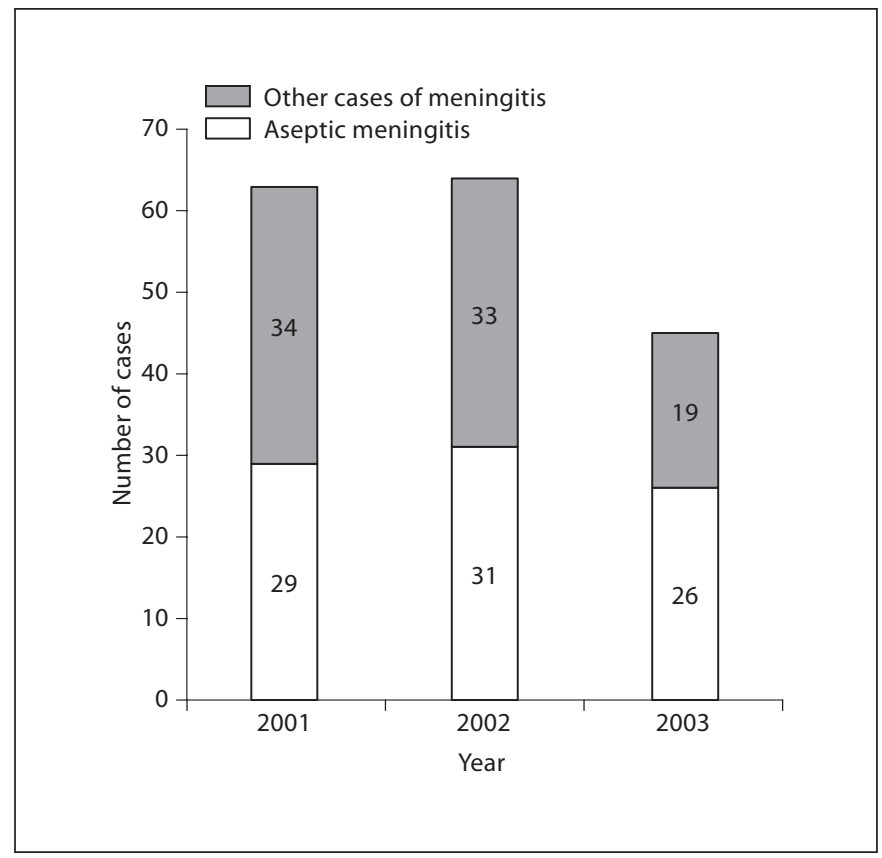

Fig. 1. Distribution of cases of aseptic meningitis during 20012003.

rial meningitis, 19 (11\%) partially treated meningitis and the remaining 86 (50\%) had aseptic meningitis. Only children who had aseptic meningitis were included in the final analysis.

\section{Demographics}

The distribution of children with aseptic meningitis throughout the study period is shown in figure 1 . There were $18(21 \%)$ neonates, $30(35 \%)$ were more than 1 month and up to 24 months old and 38 (44\%) children were more than 24 months of age. Their mean age \pm SD was $3.2 \pm$ 3.8 years (range 3 days to 12 years), and $64 \%$ were less than 5 years of age. There were 47 (55\%) male children. Fifty-six $(65 \%)$ of the cases were Kuwaiti children, while the remaining 30 (35\%) were non-Kuwaitis. None of the children had an underlying chronic medical condition or was receiving chronic steroids or immunosuppressive treatment. There were two peaks of cases with aseptic meningitis: the first was in May and June and the second was during the months of November and December (fig. 2).

\section{Clinical Presentation and CSF Findings}

The mean duration of symptoms \pm SD was $2.3 \pm 2.3$ days prior to presentation to medical care; of the 86 children, 82 (95\%) presented with fever. The mean tempera- 
Fig. 2. Seasonal distribution of cases of aseptic meningitis in Kuwait.

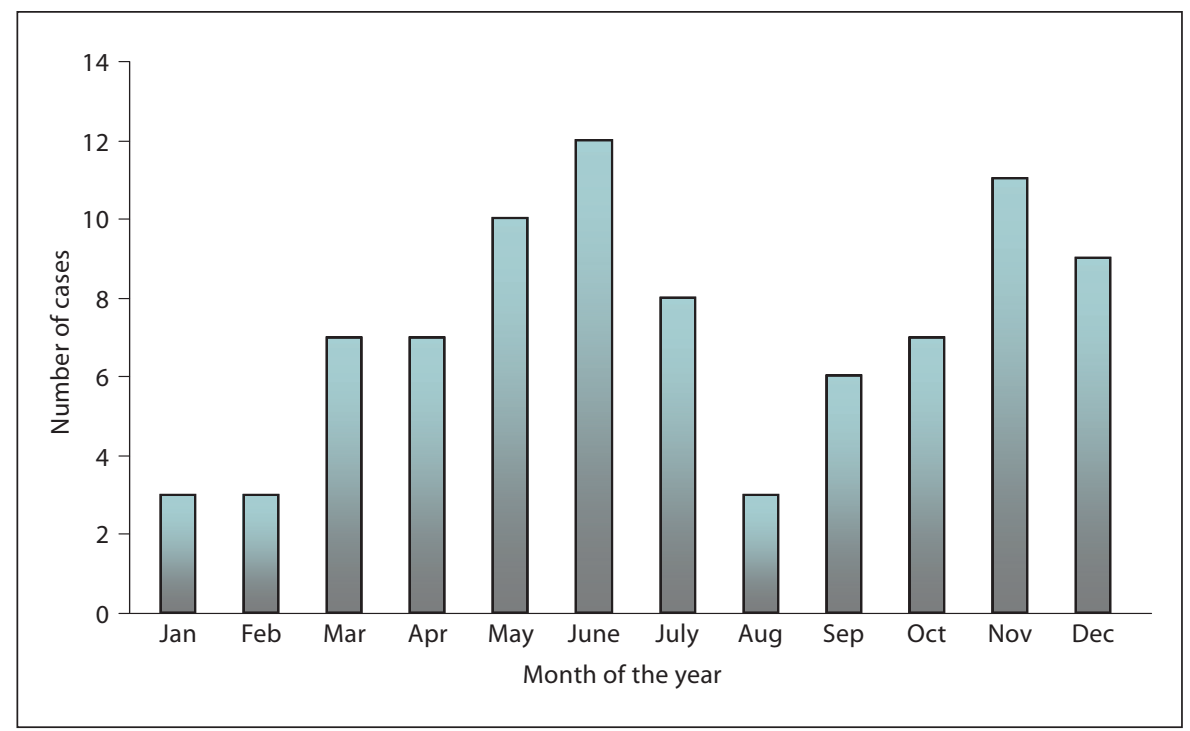

ture on admission $\pm \mathrm{SD}$ was $38.3 \pm 0.7^{\circ} \mathrm{C}$. The frequency of symptoms for children with aseptic meningitis is given in table 1. Symptoms suggestive of meningeal irritation (headache, neck stiffness and/or photophobia) were seen more frequently in children aged 5 years and older. Nonspecific symptoms (rash, diarrhea and/or cough) were seen more frequently in children less than 5 years of age. However, the difference was not statistically significant. The mean CSF WBC count \pm SD after correcting for traumatic lumbar punctures was $366 \pm 543$ $\mathrm{WBC} / \mathrm{mm}^{3}$ with lymphocytes $50 \pm 30.76 \%$. The mean glucose level $\pm \mathrm{SD}$ was $3.6 \pm 2.5 \mathrm{mmol} / \mathrm{l}$ and the mean protein level $\pm \mathrm{SD}$ was $0.665 \pm 0.523 \mathrm{mg} / \mathrm{dl}$.

\section{Management and Outcomes}

All patients received antibiotics on admission awaiting culture results. The most commonly administered antibiotics were cefotaxime $(43 \%)$ or a combination of ampicillin and cefotaxime (34\%). In addition, 7 (8\%) patients received acyclovir. The median duration of hospitalization was 7 days (range 2-22 days). Despite negative CSF cultures, antibiotics were continued to be administered for 7-10 days in $65 \%$ of the children. Other medications were administered including: steroids in 7 (8.4\%), anticonvulsants in 4 (4.8\%), and mannitol in 1 (1.2\%). The majority ( $87 \%)$ of children were afebrile by the third day of hospitalization. Complications during hospitalization were documented in $6(7 \%)$ patients and included the following: convulsions in 3 patients, mechanical ventilation in 2 patients, and motor weakness in 1 patient. Of the 16 head CT scans performed, only 3 had abnormal find-
Table 1. Frequency of symptoms in children presenting with aseptic meningitis

\begin{tabular}{lllll}
\hline Symptom & $\begin{array}{l}\text { Total } \\
(\mathrm{n}=86)\end{array}$ & $\begin{array}{l}\text { Children } \leq 5 \\
\text { years }(\mathrm{n}=55)\end{array}$ & $\begin{array}{l}\text { Children }>5 \\
\text { years }(\mathrm{n}=31)\end{array}$ & $\begin{array}{l}\mathrm{p} \\
\text { value }\end{array}$ \\
\hline Decreased oral feeding & $41(47.7)$ & $32(58)$ & $9(29)$ & $<0.01$ \\
Vomiting & $44(51.2)$ & $18(33)$ & $26(84)$ & $<0.01$ \\
Headache & $34(39.5)$ & $6(10)$ & $28(90)$ & $<0.01$ \\
Neck stiffness & $26(30)$ & $5(9)$ & $21(68)$ & $<0.01$ \\
Sleepy & $13(15)$ & $5(9)$ & $8(25)$ & $\mathrm{NS}$ \\
Cough & $13(15)$ & $11(20)$ & $2(6)$ & $\mathrm{NS}$ \\
Nausea & $12(14)$ & $3(5)$ & $9(29)$ & $<0.01$ \\
Diarrhea & $9(10.5)$ & $7(13)$ & $2(6)$ & $\mathrm{NS}$ \\
Convulsions & $5(6)$ & $4(7)$ & $1(3)$ & $\mathrm{NS}$ \\
Photophobia & $3(3.5)$ & - & $3(10)$ & $\mathrm{NS}$ \\
\hline
\end{tabular}

Figures in parentheses are percentages.

ings, which were: prominent CSF spaces, hypodense area, and subdural collection. Intensive care unit admission was necessary in 3 children: for mechanical ventilatory support in 2 patients and for refractory convulsions in the third. All children were discharged home without sequelae. There were no mortalities in the study group.

\section{Discussion}

Enterovirus-related aseptic meningitis is diagnosed year-round but is known to more frequently occur during the summer and fall $[7,8]$. The two peaks observed in the 
present study appear to be consistent with reported outbreaks of aseptic meningitis. In Kuwait, the summer months begin in April and end in September/October. The low numbers seen in August could be due to the fact that many people travel out of Kuwait for summer vacation. The November peak could be the fall outbreak. Enteroviruses might be the main underlying etiology of the summer aseptic meningitis, while the fall peak could be due to other causes of viral meningitis or other serotypes of enteroviruses.

The $21 \%$ of neonates with aseptic meningitis in the present study is lower than the $41 \%$ reported by Lin et al. [9], which might be related to the fact that we did not include patients in neonatal units. Meningismus and headache were more common in older children, similar to what was described by Lee et al. [7]. Nonspecific symptoms which might indicate viral infection, such as cough and diarrhea, were more noticeable in younger children. Thus, the diagnosis of meningitis may be missed due to the existence of nonspecific symptoms.

In spite of the excellent outcome and no mortalities of aseptic meningitis among children in Kuwait, prolonged hospitalization and unnecessarily prolonged use of antibiotics represented the main morbidity as observed by Tee et al. [10] where $96.6 \%$ of children with aseptic meningitis received antibiotics for a median of 5.5 days and had a median length of stay of 7 days. With the recently introduced reverse transcriptase-polymerase chain reaction technique $[11,12]$ that can easily detect enterovirus RNA in CSF, hospital stay has been shortened by $30 \mathrm{~h}$, and the use of antibiotics was less [13]. It is planned to introduce this molecular technique in our hospitals to avoid prolonged parenteral antibiotics and hospitalization.

The major limitation of this study was the lack of viral identification in the CSF, as rapid molecular techniques were not available. In addition, we were unable to capture all the cases of aseptic meningitis during the years of the study either because they were admitted to the private sector or had parents who declined lumbar puncture. Despite these limitations, the cohort of children in this study reflects the epidemiological, clinical features and the outcome of aseptic meningitis in Kuwait.

\section{Conclusion}

This study shows that aseptic meningitis represents a major morbidity among children in Kuwait resulting in prolonged hospitalization and unnecessarily prolonged use of antibiotics.

\section{Acknowledgments}

The authors would like to thank the followings chairpersons of the Departments of Pediatrics in the participating hospitals for their help in the approval to conduct the study in the respective hospitals: Dr. Mona Al-Khawari (Al-Amiri Hospital), Prof. Ali Mossa (Mubarak Al-Kabeer Hospital), Dr. Qusai Al-Saleh (AlFarwania Hospital), Dr. Zahra Qabazard (Al-Adan Hospital), Dr. Fayka Al-Raqam (Al-Sabah Hospital), Dr. Mohammed Oweidha (Al-Jahra Hospital).

\section{References}

1 Tunkel AR, Scheld WM: Acute meningitis; in Mandell GL, Bennett JE, Dolin R (eds): Principles and Practice of Infectious Diseases. Philadelphia, Elsevier Churchill Livingstone, 2005, pp 1083-1127.

$\checkmark 2$ Rotbart HA: Enteroviral infection of the central nervous system. Clin Infect Dis 1995; 20:971-981.

$\checkmark 3$ Wilfert CM, Lehrman SN, Katz SL: Enteroviruses and meningitis. Pediatr Infect Dis 1983;2:333-341.

4 Shaltout AA, Auger LT, Awadallah NB, Hijazi Z, Johny M, Hajj KE, Kandil H: Morbidity and mortality of bacterial meningitis in Arab children. J Trop Med Hyg 1989;92:402-406.

5 Husain EH, Al-Shawaf F, Bahbahani E, ElNabi MH, Al-Fotooh KA, Shafiq MH, AlAteeqi N, Talib MA: Epidemiology of childhood meningitis in Kuwait. Med Sci Monit 2007; 13:220-223.
6 Sarff LD, Platt LH, McCracken GH Jr: Cerebrospinal fluid evaluation in neonates: comparison of high-risk infants with and without meningitis. J Pediatr 1976;88:473-477.

77 Lee BE, Chawla R, Langley JM, Forgie SE, AlHosni M, Baerg K, Husain E, Strong J, Robinson JL, Allen U, Law BJ, Dobson S, Davies $\mathrm{HD}$ : Pediatric Investigators Collaborative Network on Infections in Canada (PICNIC) study of aseptic meningitis. BMC Infect Dis 2006;6:68

$\checkmark 8$ Lee KY, Burgner D, Lee HS, Hong JH, Lee $\mathrm{MH}$, Kang JH, Lee BC: The changing epidemiology of pediatric aseptic meningitis in Daejeon, Korea from 1987 to 2003. BMC Infect Dis 2005;5:97.

$\checkmark 9$ Lin TY, Kao HT, Hsieh SH, Huang YC, Chiu $\mathrm{CH}$, Chou YH, Yang PH, Lin RI, Tsao KC, Hsu KH, Chang LY: Neonatal enterovirus infections: emphasis on risk factors of severe and fatal infections. Pediatr Infect Dis 2003;22:889-894.
10 Tee WS, Choong CT, Lin RV, Ling AE: Aseptic meningitis in children: the Singapore experience. Ann Acad Med Singapore 2002;31: 756-760.

11 Romero JR: Reverse transcription polymerase chain reaction detection of the enteroviruses: overview and clinical utility in pediatric enteroviral infections. Arch Pathol Lab Med 1999;123:1611-1619.

$>12$ Carroll KC, Taggart B, Robison J, Byington C, Hillyard D: Evaluation of the Roche AMPLICOR enterovirus PCR assay in the diagnosis of enteroviral central nervous system infections. J Clin Virol 2000;19:149-156.

13 Ramers C, Billman G, Hartin M, Ho S, Sawyer $\mathrm{MH}$ : Impact of a diagnostic cerebrospinal fluid enterovirus polymerase chain reaction test on patient management. JAMA 2000;283:2680-2685. 